\title{
Predictive model for long-term patient satisfaction after surgery for grade I degenerative lumbar spondylolisthesis: insights from the Quality Outcomes Database
}

\author{
Praveen V. Mummaneni, MD, ${ }^{1}$ Mohamad Bydon, MD, ${ }^{2}$ Mohammed Ali Alvi, MBBS, ${ }^{2}$ \\ Andrew K. Chan, MD, ${ }^{1}$ Steven D. Glassman, MD, ${ }^{3}$ Kevin T. Foley, MD, ${ }^{4}$ Eric A. Potts, MD, ${ }^{5}$ \\ Christopher I. Shaffrey, MD, ${ }^{6}$ Mark E. Shaffrey, MD, ${ }^{6}$ Domagoj Coric, MD, \\ John J. Knightly, MD, ${ }^{8}$ Paul Park, MD, ${ }^{9}$ Michael Y. Wang, MD, ${ }^{10}$ Kai-Ming Fu, MD, PhD, ${ }^{11}$ \\ Jonathan R. Slotkin, MD,12 Anthony L. Asher, MD, ${ }^{7}$ Michael S. Virk, MD, PhD, ${ }^{11}$ \\ Panagiotis Kerezoudis, MD, MS, ${ }^{2}$ Jian Guan, MD, ${ }^{13}$ Regis W. Haid, MD, ${ }^{14}$ and \\ Erica F. Bisson, MD, MPH ${ }^{13}$
}

\begin{abstract}
1Department of Neurological Surgery, University of California, San Francisco, California; ${ }^{2}$ Department of Neurological Surgery, Mayo Clinic, Rochester, Minnesota; ${ }^{3}$ Norton Leatherman Spine Center, Louisville, Kentucky; ${ }^{4}$ Department of Neurological Surgery, University of Tennessee; Semmes Murphey Neurologic and Spine Institute, Memphis, Tennessee; ${ }^{5}$ Department of Neurological Surgery, Indiana University; Goodman Campbell Brain and Spine, Indianapolis, Indiana; ${ }^{6}$ Duke Neurosurgery and Orthopaedic Surgery, Duke University Medical Center, Durham; ${ }^{7}$ Neuroscience Institute, Carolinas Healthcare System, and Carolina Neurosurgery \& Spine Associates, Charlotte, North Carolina; ${ }^{8}$ Atlantic Neurosurgical Specialists, Morristown, New Jersey; ${ }^{9}$ Department of Neurological Surgery, University of Michigan, Ann Arbor, Michigan; ${ }^{10}$ Department of Neurological Surgery, University of Miami, Florida; ${ }^{11}$ Department of Neurological Surgery, Weill Cornell Medical Center, New York, New York; ${ }^{12}$ Geisinger Health, Danville, Pennsylvania; ${ }^{13}$ Atlanta Brain and Spine Care, Atlanta, Georgia; and ${ }^{14}$ Department of Neurological Surgery, University of Utah, Salt Lake City, Utah
\end{abstract}

OBJECTIVE Since the enactment of the Affordable Care Act in 2010, providers and hospitals have increasingly prioritized patient-centered outcomes such as patient satisfaction in an effort to adapt the "value"-based healthcare model. In the current study, the authors queried a prospectively maintained multiinstitutional spine registry to construct a predictive model for long-term patient satisfaction among patients undergoing surgery for Meyerding grade I lumbar spondylolisthesis.

METHODS The authors queried the Quality Outcomes Database for patients undergoing surgery for grade I lumbar spondylolisthesis between July 1, 2014, and June 30,2016. The primary outcome of interest for the current study was patient satisfaction as measured by the North American Spine Surgery patient satisfaction index, which is measured on a scale of 1-4, with 1 indicating most satisfied and 4 indicating least satisfied. In order to identify predictors of higher satisfaction, the authors fitted a multivariable proportional odds logistic regression model for $\geq 2$ years of patient satisfaction after adjusting for an array of clinical and patient-specific factors. The absolute importance of each covariate in the model was computed using an importance metric defined as Wald chi-square penalized by the predictor degrees of freedom.

RESULTS A total of 502 patients, out of a cohort of 608 patients (82.5\%) with grade I lumbar spondylolisthesis, undergoing either 1 - or 2-level decompression $(22.5 \%, n=113)$ or 1 -level decompression and fusion $(77.5 \%, n=389)$, met the inclusion criteria; of these, $82.1 \%(n=412)$ were satisfied after 2 years. On univariate analysis, satisfied patients were more likely to be employed and working $(41.7 \%, n=172$, vs $24.4 \%, n=22$; overall $p=0.001)$, more likely to present with predominant leg pain $(23.1 \%, n=95$, vs $11.1 \%, n=10$; overall $p=0.02)$ but more likely to present with lower Numeric Rating Scale score for leg pain (median and IQR score: 7 [5-9] vs 8 [6-9]; $p=0.05$ ). Multivariable proportional odds logistic regression revealed that older age (OR 1.57, 95\% Cl 1.09-2.76; $p=0.009)$, preoperative active employment (OR $2.06,95 \% \mathrm{Cl} 1.27-3.67 ; p=0.015)$, and fusion surgery (OR 2.3, 95\% Cl 1.30-4.06; $p=0.002)$ were the most important predictors of achieving satisfaction with surgical outcome.

ABBREVIATIONS ASA = American Society of Anesthesiologists; BMI = body mass index; CAD = coronary artery disease; LOS = length of stay; NASS = North American Spine Surgery; NRS = Numeric Rating Scale; ODI = Oswestry Disability Index; PRO = patient-reported outcome; QOD = Quality Outcomes Database SUBMITTED December 28, 2018. ACCEPTED February 6, 2019. INCLUDE WHEN CITING DOI: 10.3171/2019.2.FOCUS18734. 
CONCLUSIONS Current findings from a large multiinstitutional study indicate that most patients undergoing surgery for grade I lumbar spondylolisthesis achieved long-term satisfaction. Moreover, the authors found that older age, preoperative active employment, and fusion surgery are associated with higher odds of achieving satisfaction.

https://thejns.org/doi/abs/10.3171/2019.2.FOCUS18734

KEYWORDS patient satisfaction; outcomes; spine surgery; Quality Outcomes Database; QOD; spondylolisthesis; laminectomy; decompression; arthrodesis; fusion

$\mathrm{D}$ EGENERATIVE lumbar spondylolisthesis is one of the most common causes of low-back pain, with a reported prevalence of $11.5 \%$ in the United States. ${ }^{27}$ Surgical intervention may be considered for carefully selected patients in whom conservative management has failed, and it has been found to be associated with superior outcomes compared to nonsurgical therapy for this subset of patients. ${ }^{41}$ However, it remains unclear what factors are associated with optimum patient-reported outcomes (PROs).

Since the enactment of the Patient Protection and the Affordable Care Act of 2010, providers and hospitals have increasingly prioritized patient-centered outcomes in an effort to adapt the "value"-based healthcare model that is geared toward increasing access and quality of healthcare while simultaneously controlling cost. ${ }^{22}$ In its annual report to Congress on National Quality Strategy for Quality Improvement, the Department of Health and Human Services listed "patient satisfaction" as one of the metrics of public reporting to improve quality. ${ }^{2}$ Low-back pain and spinal surgery have been increasingly targeted for quality improvement initiatives in recent years due to the high prevalence and also the billions of dollars in direct and indirect cost associated with treating low-back pain. ${ }^{30,36,38}$

In the current study, we queried a prospectively maintained multiinstitutional spine registry to construct a predictive model for long-term patient satisfaction by using demographic, clinical, and operative factors obtained in patients undergoing surgery for grade I lumbar spondylolisthesis.

\section{Methods \\ Cohort}

We queried the Quality Outcomes Database (QOD) for patients undergoing surgery for Meyerding grade I degenerative lumbar spondylolisthesis between July 1, 2014, and June 30,2016. The QOD is a prospective, multiinstitutional registry, established in 2012, with the objective to assess risk-adjusted expected morbidity and 30-day and 12-month PROs and clinical outcomes in order to establish a data-driven mechanism of providing insights into improving quality of care for routinely performed spine surgeries in the United States. ${ }^{16,32}$ As of December 2018, over 107,000 patients across 216 participating sites nationwide have been enrolled in the Spine Surgery QOD (https://www.neuropoint.org/registries/qod/). Among these sites, 12 sites came together to initiate a focused project to assess the impact of fusion on PROs in patients undergoing surgery for grade I lumbar spondylolisthe- sis..$^{7-10,35}$ This focused group consisted of 1) sites with a study coordinator and 2) a centralized auditing mechanism to ensure data accuracy. To determine the diagnosis of grade I spondylolisthesis, surgeons at each of the participating sites evaluated preoperative standing or dynamic radiographs..$^{7-10,35}$ Intraoperative variables, including laminectomy performed, fusion performed, and number of levels of fusion or laminectomy, and minimally invasive versus open surgery, were also abstracted for all eligible patients ${ }^{7-10,35}$ For the current article, we only included patients who underwent elective 1- or 2-level decompression or 1-level decompression and fusion for grade I spondylolisthesis, according to the Meyerding classification, ${ }^{33}$ and who had available data for North American Spine Surgery (NASS) satisfaction after 2 years.

\section{Outcome of Interest}

The primary outcome of interest for the current study was patient satisfaction after 2 years, as defined by the NASS patient satisfaction index, which is measured on a scale of $1-4$, with the choices representing, respectively: "the treatment met my expectations" (score of 1), "I did not improve as much as I had hoped, but I would undergo the same treatment for the same outcome" (score of 2), "I did not improve as much as I had hoped, and I would not undergo the same treatment for the same outcome" (score of 3), and "I am the same or worse than before treatment" (score of 4). For descriptive univariate analysis, patients were classified as following: patients with NASS satisfaction scores of 1 and 2 were considered "satisfied" while patients with scores of 3 and 4 were considered "not satisfied." This binary categorization captured patients who would undergo surgery again (i.e., scores 1 and 2) compared with those who would not be willing to undergo surgery again (i.e., scores 3 and 4). In addition, for our multivariable proportional odds logistic regression model, we used the NASS satisfaction score in its natural ranked order with 1 indicating highest satisfaction and 4 indicating lowest satisfaction.

\section{Covariates}

The following covariates were included in the analysis: ${ }^{7-10,35}$ demographic characteristics, including age, sex, body mass index (BMI), ethnicity, type of insurance, education level, employment status, workers' compensation; comorbidities, including smoking status, diabetes, anxiety, osteoporosis, depression, American Society of Anesthesiologists (ASA) classification; clinical characteristics such as symptom duration, dominant symptom, am- 
bulatory status, presence of a motor deficit; and baseline PROs, including Oswestry Disability Index (ODI), ${ }^{19}$ EQ$5 \mathrm{D}$ score, ${ }^{18}$ and Numeric Rating Scale (NRS) back and leg pain scores. ${ }^{28}$ Other surgical variables, such as intraoperative blood loss, operative time, placement of an interbody graft, and employment of minimally invasive techniques, were also documented. A case was classified as a minimally invasive procedure if there was documentation of utilization of percutaneous or tubular screw fixation or tubular laminectomy, with or without intervertebral body graft placement.

\section{Statistical Analysis}

Continuous variables were summarized using medians with interquartile ranges (IQRs), while categorical variables were summarized using frequencies with proportions. In order to identify predictors of higher satisfaction, we fitted a multivariable proportional odds logistic regression model for $\geq 2$ years of patient satisfaction after adjusting for age, BMI, sex, insurance status, education status, employment status at the time of surgery, dominant symptom, length of stay (LOS), coronary artery disease (CAD), diabetes, anxiety, depression, osteoporosis, baseline ODI score, EQ-5D score, NRS back and leg score, ambulation status, symptom duration, ASA class, and discharge disposition. Odds ratios were obtained by exponentiating the estimates obtained from the regression model. Furthermore, we also analyzed the absolute importance of each covariate in the model on predicting patient satisfaction by using an importance metric defined as Wald chi-square penalized by the predictor degrees of freedom. ${ }^{25}$ As per this method, the higher the metric, the more important the variable. The analysis was performed using R 3.1.2 (R: A language and environment for statistical computing. $\mathrm{R}$ Foundation for Statistical Computing. https://www.R-project.org) and Package rms. p values were two-tailed and were considered significant at $<0.05$.

\section{Results}

A total of 502 patients, out of a cohort of 608 patients $(82.5 \%)$, with grade I lumbar spondylolisthesis, undergoing either a 1- or 2-level decompression $(22.5 \%, \mathrm{n}=113)$ or 1-level decompression and fusion $(77.5 \%, \mathrm{n}=389)$ met the inclusion criteria. Among these, 61.5\% ( $\mathrm{n}=309)$ had an NASS satisfaction score of 1 (highest satisfaction), $20.5 \%$ $(\mathrm{n}=103)$ had a score of $2,7.56 \%(\mathrm{n}=38)$ had a score of 3 , and $10.3 \%(n=52)$ had a satisfaction score of 4 (lowest satisfaction) (Table 1). Patients with a score of 1 or 2 were classified as satisfied $(n=412)$, while patients with a score of 3 or 4 were classified as not satisfied $(n=90)$.

\section{Demographic Characteristics}

Patients who were satisfied did not differ significantly from those who were not satisfied in terms of age (median 63.1 [IQR 55.7-70.9] vs 61 [IQR 51.2-71]; $\mathrm{p}=0.16)$, sex (females: $60 \%, \mathrm{n}=54$, vs $57.5 \%, \mathrm{n}=237$; $\mathrm{p}=0.666$ ), ethnicity (Hispanic: $4.6 \%, \mathrm{n}=19$, vs $4.4 \%, \mathrm{n}=4$; overall $\mathrm{p}=$ 0.976), BMI (median 29.2 [IQR 25.6-33.6] vs 29.7 [IQR 26.3-34.9]; $\mathrm{p}=0.33$ ), or education status (college and above: $57.6 \%, \mathrm{n}=232$, vs $51.1 \%, \mathrm{n}=44$; overall $\mathrm{p}=0.86$ ).
TABLE 1. Distribution of patient satisfaction scores

\begin{tabular}{ccc}
\hline Score & NASS Satisfaction Measure ${ }^{15}$ & $\begin{array}{c}\text { No. of Patients } \\
(\%)\end{array}$ \\
\hline 1 & The treatment met my expectations & $309(61.5 \%)$ \\
\hline 2 & $\begin{array}{l}\text { I did not improve as much as I had hoped, but } \\
\text { I would undergo the same treatment for the } \\
\text { same outcome }\end{array}$ & $103(20.5 \%)$ \\
\hline 3 & I did not improve as much as I had hoped, \\
& $\begin{array}{l}\text { and I would not undergo the same treat- } \\
\text { ment for the same outcome }\end{array}$ & $38(7.6 \%)$ \\
\hline 4 & I am the same or worse than before treatment & $52(10.3 \%)$ \\
\hline Total & & 502 \\
\hline
\end{tabular}

We also found no difference in insurance status between patients satisfied and not satisfied at follow-up (private insurance: $51.7 \%, \mathrm{n}=213$, vs $52.2 \%, \mathrm{n}=47$; Medicare: $40.3 \%, \mathrm{n}=166$, vs $37.8 \%, \mathrm{n}=34$; Medicaid: $5.1 \%, \mathrm{n}=21$, vs $7.8 \%, \mathrm{n}=7$; Veterans Affairs/government: $2.7 \%, \mathrm{n}=11$, vs $2.2 \%, n=11$; overall $\mathrm{p}=0.853$ ). Satisfied patients were more likely to have workers' compensation compared to those who were not satisfied $(4.9 \%, \mathrm{n}=20$, vs $2.2 \%, \mathrm{n}=$ $2 ; \mathrm{p}=0.006)$. Finally, satisfied patients were more likely to be employed and working, compared to those who were not satisfied $(41.7 \%, \mathrm{n}=172$, vs $24.4 \%, \mathrm{n}=22$; overall $\mathrm{p}=$ 0.001). These results are summarized in Table 2 .

\section{Baseline Clinical Characteristics, Comorbidities, and PROs}

Compared to patients who were not satisfied with their surgery after 2 years, satisfied patients were found to have a comparable incidence of past surgery $(10.9 \%, \mathrm{n}=45$, vs $11.1 \%, \mathrm{n}=10 ; \mathrm{p}=0.96)$, diabetes $(16.3 \%, \mathrm{n}=67$, vs $18.9 \%, \mathrm{n}=17 ; \mathrm{p}=0.54), \mathrm{CAD}(10.7 \%, \mathrm{n}=44$, vs $10 \%, \mathrm{n}$ $=9 ; \mathrm{p}=0.84)$, anxiety $(17.2 \%, \mathrm{n}=71$, vs $13.3 \%, \mathrm{n}=12 ; \mathrm{p}$ $=0.367)$, depression $(18.4 \%, \mathrm{n}=76$, vs $24.4 \%, \mathrm{n}=22 ; \mathrm{p}=$ $0.193)$, and osteoporosis $(5.3 \%, \mathrm{n}=22$, vs $6.7 \%, \mathrm{n}=6 ; \mathrm{p}=$ $0.619)$. We also compared clinical characteristics between satisfied and not satisfied patients and found that satisfied patients were more likely to present with leg pain greater than back pain $(23.1 \%, \mathrm{n}=95$, vs $11.1 \%, \mathrm{n}=10)$ and less likely to present with equal degrees of leg and back pain (39.8\%, $\mathrm{n}=164$, vs $52.2 \%, \mathrm{n}=47$; overall $\mathrm{p}=0.021)$. However, the two groups did not differ in incidence of motor deficit $(24.1 \%, \mathrm{n}=99$, vs $21.1 \%, \mathrm{n}=19 ; \mathrm{p}=0.54)$, ambulation at presentation (not independent: $10.7 \%, \mathrm{n}=44$, vs $11.1 \%, \mathrm{n}=10$; overall $\mathrm{p}=0.989)$, and symptom duration (>3 months: $93.7 \%, \mathrm{n}=386$, vs $93.3 \%, \mathrm{n}=84 ; \mathrm{p}=0.93$ ). Comparing the baseline PROs between the two groups revealed similar scores in NRS-measured back pain (median 7 [IQR 6-9] vs 8 [IQR 6-9]; p = 0.73), ODI (median 48 [IQR 38-60] vs 47 [IQR 32-56]; $\mathrm{p}=0.104)$, and EQ-5D (median 0.597 [0.33-0.71] vs 0.551 [0.31-0.71]; $\mathrm{p}=721$ ); however, the not-satisfied patients were likely to present with higher NRS leg pain scores, with $\mathrm{p}$ value approaching significance (median 7 [IQR 5-9] vs 8 [IQR 6-9]; $\mathrm{p}=$ $0.05)$. These results are presented in Table 3.

\section{Operative Characteristics and Perioperative Outcomes}

On univariate analysis, patients in the two groups did 
TABLE 2. Demographic characteristics of patients stratified by satisfaction status

\begin{tabular}{|c|c|c|c|c|}
\hline Variable & Total $(n=502)$ & Not Satisfied $(n=90)$ & Satisfied $(n=412)$ & $p$ Value \\
\hline Age (yrs) & & & & 0.155 \\
\hline Median & 63 & 61 & 63.1 & \\
\hline Q1, Q3 & $55,70.9$ & $51.2,71$ & $55.7,70.9$ & \\
\hline Female, no. (\%) & $291(58.0 \%)$ & $54(60 \%)$ & $237(57.5 \%)$ & 0.666 \\
\hline Ethnicity, no. (\%) & & & & 0.976 \\
\hline Hispanic & $23(4.6 \%)$ & $4(4.4 \%)$ & $19(4.6 \%)$ & \\
\hline Non-Hispanic & $464(92.4 \%)$ & $83(92.2 \%)$ & $381(92.5 \%)$ & \\
\hline Prefer not to answer & $15(3.0 \%)$ & $3(3.3 \%)$ & $12(2.9 \%)$ & \\
\hline BMI & & & & 0.333 \\
\hline Median & 29.3 & 29.7 & 29.2 & \\
\hline Q1, Q3 & $25.7,33.7$ & $26.3,34.9$ & $25.6,33.6$ & \\
\hline Insurance, no. (\%) & & & & 0.853 \\
\hline Medicaid & $28(5.6 \%)$ & $7(7.8 \%)$ & $21(5.1 \%)$ & \\
\hline Medicare & $200(39.8 \%)$ & $34(37.8 \%)$ & $166(40.3 \%)$ & \\
\hline Private & $260(51.8 \%)$ & $47(52.2 \%)$ & $213(51.7 \%)$ & \\
\hline VA/government & $13(2.6 \%)$ & $2(2.2 \%)$ & $11(2.7 \%)$ & \\
\hline Education, no. (\%) & & & & 0.861 \\
\hline Less than high school & $14(2.8 \%)$ & $3(3.3 \%)$ & $11(2.7 \%)$ & \\
\hline High school diploma or GED & $199(39.6 \%)$ & $39(43.3 \%)$ & $160(38.8 \%)$ & \\
\hline 2-yr college degree & $87(17.3 \%)$ & $13(14.4 \%)$ & $74(18.0 \%)$ & \\
\hline 4-yr college degree & $97(19.3 \%)$ & $16(17.8 \%)$ & $81(19.7 \%)$ & \\
\hline Post-college & $92(18.3 \%)$ & $15(16.7 \%)$ & $77(18.7 \%)$ & \\
\hline Workers' compensation, no. (\%) & $22(4.4 \%)$ & $2(2.2 \%)$ & $20(4.9 \%)$ & 0.006 \\
\hline Employment, no. (\%) & & & & 0.001 \\
\hline Employed \& working & $194(38.6 \%)$ & $22(24.4 \%)$ & $172(41.7 \%)$ & \\
\hline Employed, not working & $28(5.6 \%)$ & $10(11.1 \%)$ & $18(4.4 \%)$ & \\
\hline Unemployed & $271(54.0 \%)$ & $57(63.3 \%)$ & $214(51.9 \%)$ & \\
\hline
\end{tabular}

Q1 = 25th quartile; $Q 3=75$ th quartile; VA = Veterans Affairs.

Boldface type indicates statistical significance.

not differ in incidence of higher ASA class (class 3 or 4 : $36.9 \%, \mathrm{n}=152$, vs $40.0 \%, \mathrm{n}=36 ; \mathrm{p}=0.757)$, the type of surgical approach (posterior: $90.8 \%, \mathrm{n}=374$, vs $94.4 \%$, $\mathrm{n}=85 ; \mathrm{p}=0.558)$, fusion procedure $(77.9 \%, \mathrm{n}=321$, vs $75.6 \%, \mathrm{n}=68 ; \mathrm{p}=628)$, minimally invasive decompression $(36.2 \%, \mathrm{n}=149$; vs $38.9 \%, \mathrm{n}=35 ; \mathrm{p}=0.627)$, and minimally invasive interbody $(26.9 \%, \mathrm{n}=11$, vs $17.8 \%, \mathrm{n}=$ $16 ; p=0.07)$. The two groups also did not differ in length of surgery (median 171 minutes [IQR 118-222] vs 157 minutes [IQR 116.2-230.5]; $\mathrm{p}=0.866$ ), LOS (median 3 days [IQR 2-4] vs 3 days [IQR 1-4]; $p=0.718$ ), discharge disposition (home routine: $86.7 \%, \mathrm{n}=357$, vs $82.2 \%, \mathrm{n}=$ $74 ; \mathrm{p}=0.06)$, or related reoperations $(5.8 \%, \mathrm{n}=24$, vs $10 \%$, $\mathrm{n}=9 ; \mathrm{p}=0.148)$. These results are summarized in Table 4 .

\section{Multivariable Analysis and Predictor Importance}

Multivariable proportional odds logistic regression revealed that older patients were more likely to have a higher satisfaction score (OR 1.57, 95\% CI 1.09-2.76; $\mathrm{p}=0.009$ ). Moreover, patients who were employed and working at the time of surgery, compared to those who were unemployed, were more likely to have a higher satisfaction score (OR $2.06,95 \%$ CI $1.27-3.67 ; p=0.015)$. Finally, the addition of fusion was found to be associated with a higher satisfaction score (OR 2.3, 95\% CI 1.30-4.06; $\mathrm{p}=0.002)$. These results are shown in Fig. 1. Predictor importance revealed that the most important predictors of patient satisfaction were employment (Wald $\chi^{2}=13.5$, accounting for $25.7 \%$ of total Wald $\chi^{2} ; \mathrm{p}=0.003$ ), fusion (Wald $\chi^{2}=8.4$, accounting for $16 \%$ of total Wald $\chi^{2} ; \mathrm{p}=0.003$ ), and age (Wald $\chi^{2}=5.9$, accounting for $11.2 \%$ of total Wald $\chi^{2} ; \mathrm{p}=$ 0.01). These results are summarized in Fig. 2.

\section{Discussion}

To the best of our knowledge, this is the largest study to assess predictors of long-term patient satisfaction for patients undergoing 1- or 2-level decompression or 1-level decompression and fusion for grade I spondylolisthesis. It is important to note that $82 \%$ patients were satisfied with their surgery after 2 years, having answered the NASS satisfaction questionnaire with either "the treatment met my expectations" or with "I did not improve as much as I 
TABLE 3. Comorbidities, clinical characteristics, and baseline PROs stratified by satisfaction status

\begin{tabular}{|c|c|c|c|c|}
\hline Variable & Total $(n=502)$ & Not Satisfied $(n=90)$ & Satisfied $(n=412)$ & $p$ Value \\
\hline Major past surgery, no. (\%) & $55(11.0 \%)$ & $10(11.1 \%)$ & $45(10.9 \%)$ & 0.959 \\
\hline Diabetes, no. (\%) & $84(16.7 \%)$ & $17(18.9 \%)$ & $67(16.3 \%)$ & 0.545 \\
\hline CAD, no. (\%) & $53(10.6 \%)$ & $9(10 \%)$ & $44(10.7 \%)$ & 0.849 \\
\hline Anxiety, no. (\%) & $83(16.5 \%)$ & $12(13.3 \%)$ & $71(17.2 \%)$ & 0.367 \\
\hline Depression, no. (\%) & $98(19.5 \%)$ & $22(24.4 \%)$ & $76(18.4 \%)$ & 0.193 \\
\hline Osteoporosis, no. (\%) & $28(5.6 \%)$ & $6(6.7 \%)$ & $22(5.3 \%)$ & 0.619 \\
\hline Dominant symptom, no. (\%) & & & & 0.021 \\
\hline Back pain dominant & $186(37.1 \%)$ & $33(36.7 \%)$ & $153(37.1 \%)$ & \\
\hline Back equals leg pain & $211(42.0 \%)$ & $47(52.2 \%)$ & $164(39.8 \%)$ & \\
\hline Leg pain dominant & $105(20.9 \%)$ & $10(11.1 \%)$ & $95(23.1 \%)$ & \\
\hline Motor deficit, no. (\%) & $118(23.6 \%)$ & $19(21.1 \%)$ & $99(24.1 \%)$ & 0.547 \\
\hline Ambulation, no. (\%) & & & & 0.989 \\
\hline Independently ambulatory & $448(89.2 \%)$ & $80(88.9 \%)$ & $368(89.3 \%)$ & \\
\hline Ambulatory w/ assistive device & $49(9.8 \%)$ & $9(10.0 \%)$ & $40(9.7 \%)$ & \\
\hline Wheelchair bound & $5(1.0 \%)$ & $1(1.1 \%)$ & $4(1.0 \%)$ & \\
\hline Symptom duration, no. (\%) & & & & 0.934 \\
\hline$<3$ months & $14(2.8 \%)$ & $3(3.3 \%)$ & $11(2.7 \%)$ & \\
\hline$>3$ months & $470(93.6 \%)$ & $84(93.3 \%)$ & $386(93.7 \%)$ & \\
\hline Unknown & $18(3.6 \%)$ & $3(3.3 \%)$ & $15(3.6 \%)$ & \\
\hline Baseline NRSBP score & & & & 0.737 \\
\hline Median & 7 & 8 & 7 & \\
\hline Q1, Q3 & 6,9 & 6,9 & 6,9 & \\
\hline Baseline NRSLP score & & & & 0.058 \\
\hline Median & 7 & 8 & 7 & \\
\hline Q1, Q3 & 5,9 & 6,9 & 5,9 & \\
\hline Baseline ODI score & & & & 0.104 \\
\hline Median & 48 & 47 & 48 & \\
\hline Q1, Q3 & 38,60 & 32,56 & 38,60 & \\
\hline Baseline EQ-5D score & & & & 0.721 \\
\hline Median & 0.597 & 0.551 & 0.597 & \\
\hline Q1, Q3 & $0.312,0.708$ & $0.308,0.708$ & $0.330,0.708$ & \\
\hline
\end{tabular}

NRSBP = NRS back pain; NRSLP = NRS leg pain.

Boldface type indicates statistical significance.

had hoped, but I would undergo the same treatment for the same outcome."

Among baseline demographic factors, older age was predictive of a higher satisfaction score after 2 years. This finding has previously been reported in the literature for patients undergoing lumbar surgery, notably by Crawford et al., who reported that older age was predictive of best outcomes in a cohort of 396 patients..$^{14}$ On the other hand, Sigmundsson et al. investigated 5100 patients undergoing surgery for spinal stenosis and found that older age was associated with slightly lower odds of satisfaction. ${ }^{37}$

Work-related factors are also known to impact patient outcomes after spinal surgery. Asher et al., in their analysis of 4695 patients, showed that work-related factors accounted for $33.3 \%$ of predictability of outcomes following elective lumbar surgery for degenerative surgery. ${ }^{6}$ To that end, we found that patients who were employed and working preoperatively were more likely to have higher satisfaction scores after 2 years. Active employment has previously been shown to be associated with positive outcomes following surgical intervention. ${ }^{5,6,12,24}$ This may be attributed to the fact that these represent a more driven subset of patients who have better social support, work satisfaction, healthier psychological state, availability of modified duty, optimum physical demand at work, and employer-employee relations including the availability of litigation issues. ${ }^{4,5,12,26,31,34,40}$ Together, these factors may contribute to these patients having superior outcomes after spine surgery.

Finally, the addition of fusion was found to be associated with higher satisfaction scores in our cohort. The current literature is conflicted on the role of instrumented fusion for lumbar degenerative lumbar spondylolisthesis. $^{20,21,23}$ A recent meta-analysis of 3 randomized con- 
TABLE 4. Operative characteristics and perioperative outcomes stratified by satisfaction status

\begin{tabular}{|c|c|c|c|c|}
\hline Variable & Total $(n=502)$ & Not Satisfied $(n=90)$ & Satisfied $(n=412)$ & p Value \\
\hline ASA class & & & & 0.857 \\
\hline Median & 2 & 2 & 2 & \\
\hline Q1, Q3 & 2,3 & 2,3 & 2,3 & \\
\hline Surgical approach, no. (\%) & & & & 0.558 \\
\hline Anterior & $13(2.6 \%)$ & $2(2.2 \%)$ & $11(2.7 \%)$ & \\
\hline Lateral & $7(1.4 \%)$ & $0(0.0 \%)$ & $7(1.7 \%)$ & \\
\hline Posterior & $459(91.4 \%)$ & $85(94.4 \%)$ & $374(90.8 \%)$ & \\
\hline Two-stage & $23(4.6 \%)$ & $3(3.3 \%)$ & $20(4.9 \%)$ & \\
\hline Group, no. (\%) & & & & 0.628 \\
\hline Decompression alone & $113(22.5 \%)$ & $22(24.4 \%)$ & $91(22.1 \%)$ & \\
\hline Fusion & $389(77.5 \%)$ & $68(75.6 \%)$ & $321(77.9 \%)$ & \\
\hline MIS decompression & $184(36.7 \%)$ & $35(38.9 \%)$ & $149(36.2 \%)$ & 0.627 \\
\hline MIS interbody fusion & $127(25.3 \%)$ & $16(17.8 \%)$ & $11(26.9 \%)$ & 0.070 \\
\hline Length of surgery & & & & 0.866 \\
\hline Median & 171 & 157 & 171 & \\
\hline Q1, Q3 & $117.5,222.5$ & $116.2,230.5$ & 118,222 & \\
\hline LOS & & & & 0.718 \\
\hline Median & 3 & 3 & 3 & \\
\hline Q1, Q3 & 2,4 & $1.2,4$ & 2,4 & \\
\hline Discharge disposition, no. (\%) & & & & 0.061 \\
\hline Home routine & $431(85.9 \%)$ & $74(82.2 \%)$ & $357(86.7 \%)$ & \\
\hline Home w/ home healthcare services & $25(5.0 \%)$ & $3(3.3 \%)$ & $22(5.4 \%)$ & \\
\hline Post- or non-acute care setting & $40(8.0 \%)$ & $13(14.4 \%)$ & $27(6.6 \%)$ & \\
\hline Transferred to another acute care facility & $4(0.8 \%)$ & $0(0.0 \%)$ & $4(1.0 \%)$ & \\
\hline Related reoperations & $33(6.6 \%)$ & $9(10.0 \%)$ & $24(5.8 \%)$ & 0.148 \\
\hline
\end{tabular}

MIS = minimally invasive surgery.

trolled trials and 3 observational studies showed no benefit of adding fusion in the treatment of spondylolisthesis in terms of patient satisfaction..$^{11}$ However, it is important to note that several independent observational studies have demonstrated the beneficial role of adding instrumented fusion for patients undergoing surgical intervention for degenerative spondylolisthesis. . $, 3,8,9,17^{-17}$

Some notable associations with patient satisfaction previously identified but not found to be significant in our cohort are worth discussing here. A preoperative diagnosis of depression has been found to be associated with lower odds of satisfaction in previous studies, which was not found to be significantly associated in our cohort. In their study, which analyzed preoperative factors associated with patient satisfaction scores, as documented using the Hospital Consumer Assessment of Healthcare Providers and Systems survey, Levin et al. observed that depression negatively impacted the scores..$^{29}$ Moreover, an integrative review by Strøm et al. highlighted the prevalence and challenges faced by providers and surgeons in treating spine surgery patients with anxiety and depression. ${ }^{39}$ Smoking status has also been shown to adversely affect outcomes. Crawford et al., in their analysis of 7207 patients undergoing lumbar spine surgery, found that smokers were less likely to be satisfied than nonsmokers. ${ }^{13}$ Sigmundsson et al. also reported a $41 \%$ decrease in the odds of achieving satisfaction after surgery for smokers among patients undergoing surgery for lumbar spinal stenosis. ${ }^{37}$

\section{Limitations}

Our study may have some limitations. The current study is a retrospective analysis derived from a prospectively maintained registry that has its associated limitations, most notable of which may be selection bias due to lack of standardized operative technique and patient selection. Moreover, we did not collect other important variables that have been shown to affect outcomes, such as nature of occupation, race, and socioeconomic status. Moreover, the NASS satisfaction instrument may not be an accurate measure of overall satisfaction as it is primarily dependent on whether preoperative expectations were met; a different satisfaction measure may have yielded results different from our findings. Nevertheless, the NASS satisfaction scale is still considered one of the most widely used measures for assessing patient satisfaction with clinical outcomes and not with other nonclinical factors, such as experience with allied health staff, hospital environment, and appointment process. Finally, we were also unable to investigate directly the impact of fusion status on patient satisfaction. We used related reoperations as a sur- 


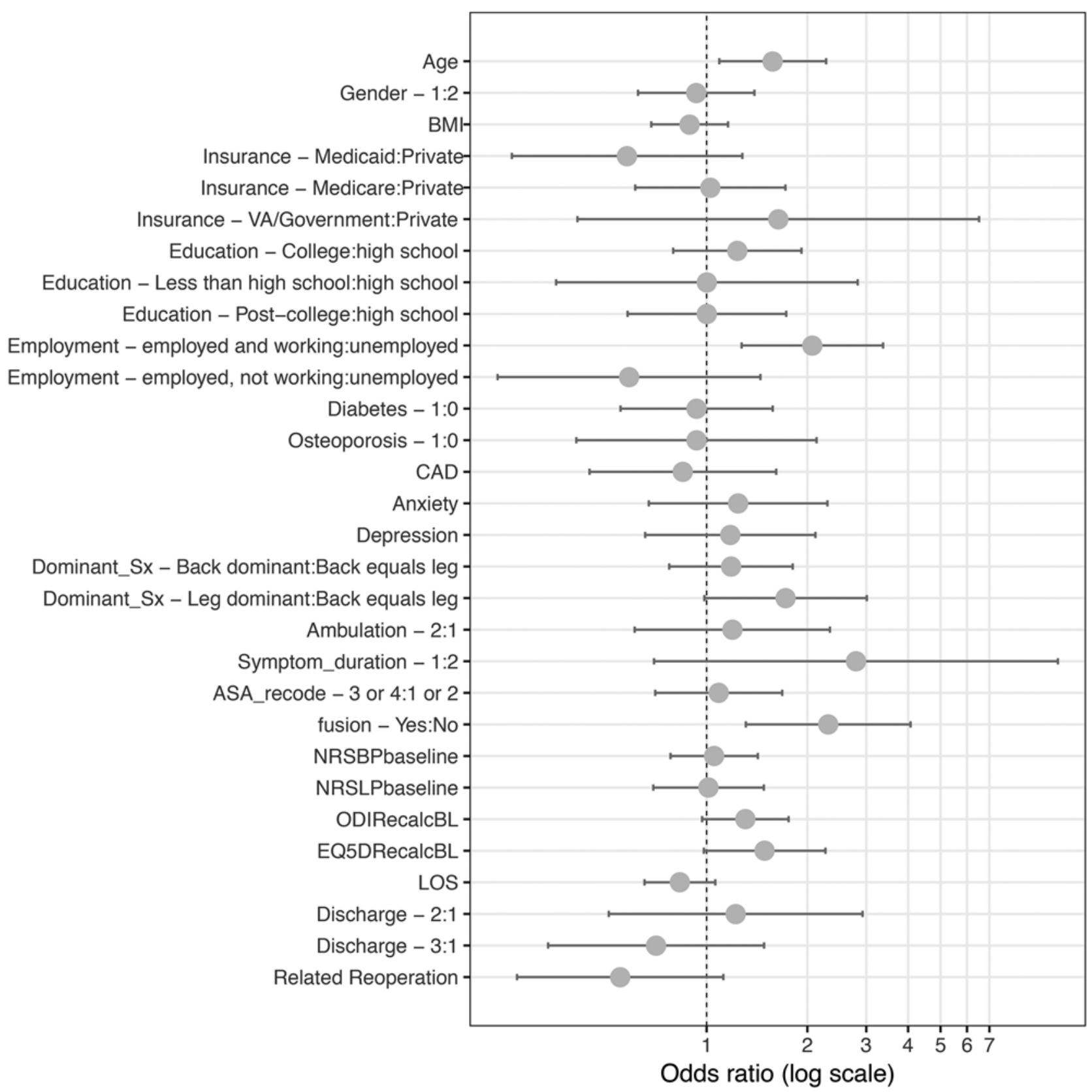

FIG. 1. Multivariable proportional odds logistic regression model for at least 2 years of patient satisfaction after surgery for grade I lumbar spondylolisthesis. NRSBP = NRS back pain; NRSLP = NRS leg pain; RecalcBL = recalculated baseline; Sx = symptom; VA = Veterans Affairs.

rogate for this factor and found that reoperation did not impact long-term satisfaction. We believe that future studies should investigate the association between fusion status at follow-up and patient satisfaction.

Despite these limitations, the current study is one of the largest to date and represents a diverse population derived from 12 institutions across the United States, utilizing prospectively maintained data to analyze patient satisfaction among a homogeneous cohort of patients with Meyerding grade I spondylolisthesis who have undergone either 1- or 2-level decompression or a 1-level fusion procedure.

\section{Conclusions}

The results from a large multiinstitutional study indicate that most patients with Meyerding grade I lumbar spondylolisthesis undergoing surgery achieved long-term satisfaction. Moreover, we found that patient age, preoperative active employment, and the addition of fusion may be associated with higher odds of achieving high level of satisfaction. These results are important in that they may help the surgeons to have a better preoperative discussion with their patients to optimize their outcomes. 


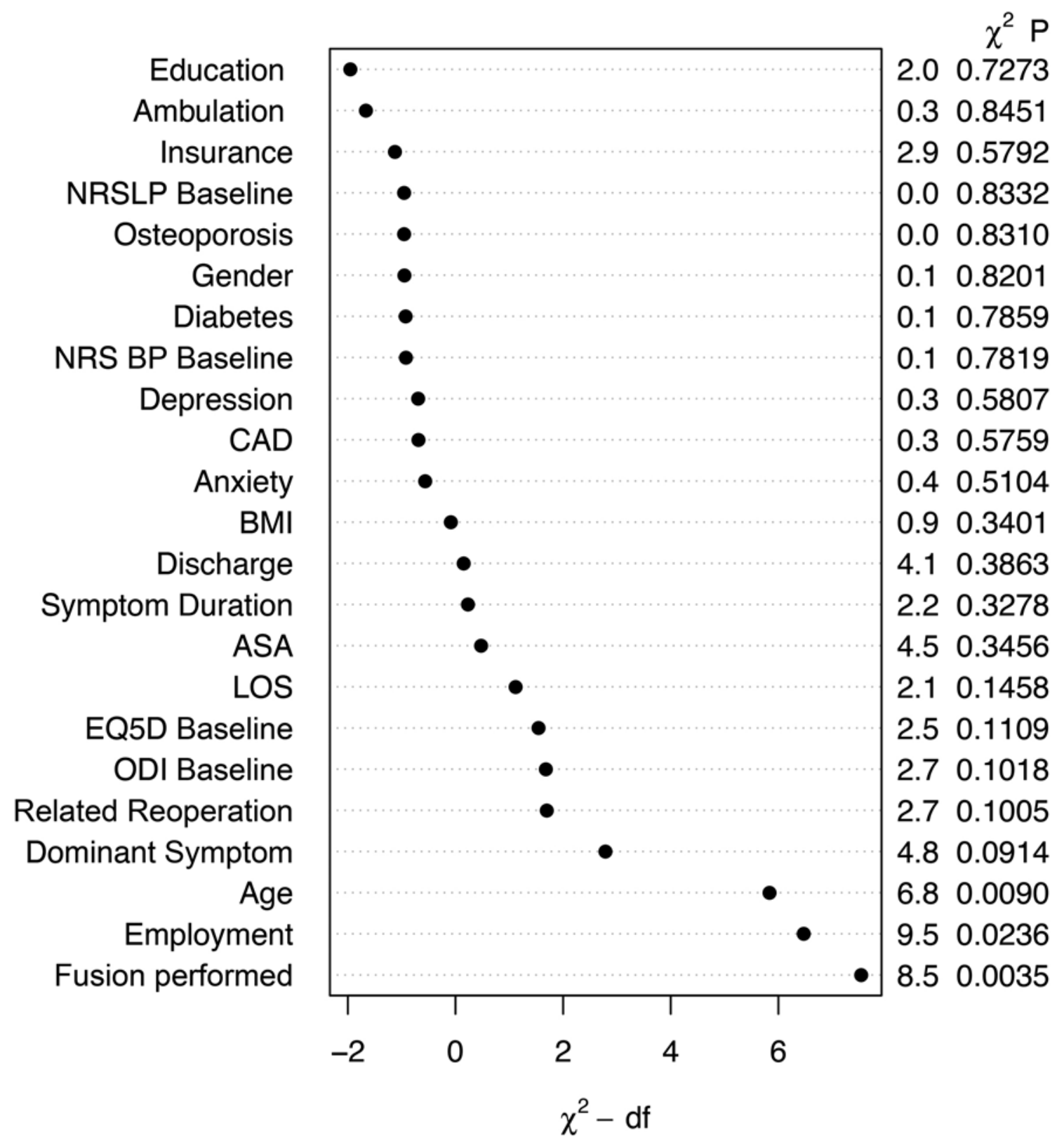

FIG. 2. Predictor importance analysis for factors associated with patient satisfaction following surgery for lumbar spondylolisthesis. $\mathrm{df}=$ degree of freedom.

\section{References}

1. Abdu WA, Lurie JD, Spratt KF, Tosteson ANA, Zhao W, Tosteson TD, et al: Degenerative spondylolisthesis: does fusion method influence outcome? Four-year results of the spine patient outcomes research trial. Spine (Phila Pa 1976) 34:2351-2360, 2009

2. Agency for Healthcare Research and Quality: 2011 Report to Congress: National Strategy for Quality Improvement in Health Care. Washington, DC: Department of Health and Human Services, 2011 (https://www.ahrq.gov/workingforquality/reports/2011-annual-report.html) [Accessed March 8, 2019]

3. Andersen T, Christensen FB, Niedermann B, Helmig P, Høy $\mathrm{K}$, Hansen ES, et al: Impact of instrumentation in lumbar spinal fusion in elderly patients: 71 patients followed for $2-7$ years. Acta Orthop 80:445-450, 2009

4. Anderson JT, Haas AR, Percy R, Woods ST, Ahn UM, Ahn NU: Return to work after diskogenic fusion in workers' compensation subjects. Orthopedics 38:e1065-e1072, 2015

5. Anderson PA, Schwaegler PE, Cize k D, Leverson G: Work status as a predictor of surgical outcome of discogenic low back pain. Spine (Phila Pa 1976) 31:2510-2515, 2006

6. Asher AL, Devin CJ, Archer KR, Chotai S, Parker SL, Bydon M, et al: An analysis from the Quality Outcomes Database, Part 2. Predictive model for return to work after elective surgery for lumbar degenerative disease. J Neurosurg Spine 27:370-381, 2017

7. Asher AL, Kerezoudis P, Mummaneni PV, Bisson EF, Glass- 
man SD, Foley KT, et al: Defining the minimum clinically important difference for grade I degenerative lumbar spondylolisthesis: insights from the Quality Outcomes Database. Neurosurg Focus 44(1):E2, 2018

8. Chan AK, Bisson EF, Bydon M, Glassman SD, Foley KT, Potts EA, et al: Laminectomy alone versus fusion for grade 1 lumbar spondylolisthesis in 426 patients from the prospective Quality Outcomes Database. J Neurosurg Spine 30:234241, 2018 (Erratum in J Neurosurg Spine [epub ahead of print February 22, 2019; DOI: 10.3171/2019.1.SPINE17913a])

9. Chan AK, Bisson EF, Bydon M, Glassman SD, Foley KT, Potts EA, et al: Obese patients benefit, but do not fare as well as nonobese patients, following lumbar spondylolisthesis surgery: an analysis of the quality outcomes database. Neurosurgery [epub ahead of print], 2018

10. Chan AK, Bisson EF, Bydon M, Glassman SD, Foley KT, Potts EA, et al: Women fare best following surgery for degenerative lumbar spondylolisthesis: a comparison of the most and least satisfied patients utilizing data from the Quality Outcomes Database. Neurosurg Focus 44(1):E3, 2018

11. Chen Z, Xie P, Feng F, Chhantyal K, Yang Y, Rong L: Decompression alone versus decompression and fusion for lumbar degenerative spondylolisthesis: a meta-analysis. World Neurosurg 111:e165-e177, 2018

12. Cole DC, Ibrahim S, Shannon HS, Scott FE, Eyles J: Work and life stressors and psychological distress in the Canadian working population: a structural equation modelling approach to analysis of the 1994 National Population Health Survey. Chronic Dis Can 23:91-99, 2002

13. Crawford CH III, Carreon LY, Bydon M, Asher AL, Glassman SD: Impact of preoperative diagnosis on patient satisfaction following lumbar spine surgery. J Neurosurg Spine 26:709-715, 2017

14. Crawford CH III, Glassman SD, Djurasovic M, Owens RK II, Gum JL, Carreon LY: Prognostic factors associated with best outcomes (minimal symptom state) following fusion for lumbar degenerative conditions. Spine J 19:187-190, 2019

15. Daltroy LH, Cats-Baril WL, Katz JN, Fossel AH, Liang MH; The North American Spine Society lumbar spine outcome assessment instrument: reliability and validity tests. Spine (Phila Pa 1976) 21:741-749, 1996

16. Devin CJ, Bydon M, Alvi MA, Kerezoudis P, Khan I, Sivaganesan A, et al: A predictive model and nomogram for predicting return to work at 3 months after cervical spine surgery: an analysis from the Quality Outcomes Database. Neurosurg Focus 45(5):E9, 2018

17. Endler P, Ekman P, Möller H, Gerdhem P: Outcomes of posterolateral fusion with and without instrumentation and of interbody fusion for isthmic spondylolisthesis: a prospective study. J Bone Joint Surg Am 99:743-752, 2017

18. EuroQol Group: EuroQol-a new facility for the measurement of health-related quality of life. Health Policy 16:199_ 208, 1990

19. Fairbank JC, Pynsent PB: The Oswestry Disability Index. Spine (Phila Pa 1976) 25:2940-2952, 2000

20. Försth P, Michaëlsson K, Sandén B: Does fusion improve the outcome after decompressive surgery for lumbar spinal stenosis?: a two-year follow-up study involving 5390 patients. Bone Joint J 95-B:960-965, 2013

21. Försth P, Ólafsson G, Carlsson T, Frost A, Borgström F, Fritzell P, et al: A randomized, controlled trial of fusion surgery for lumbar spinal stenosis. N Engl J Med 374:1413-1423, 2016

22. Gentry S, Badrinath P: Defining health in the era of valuebased care: lessons from England of relevance to other health systems. Cureus 9:e1079, 2017

23. Ghogawala Z, Dziura J, Butler WE, Dai F, Terrin N, Magge $\mathrm{SN}$, et al: Laminectomy plus fusion versus laminectomy alone for lumbar spondylolisthesis. N Engl J Med 374:14241434,2016
24. Gum JL, Glassman SD, Carreon LY: Is type of compensation a predictor of outcome after lumbar fusion? Spine (Phila Pa 1976) 38:443-448, 2013

25. Harrell FE Jr: Regression Modeling Strategies: With Applications to Linear Models, Logistic and Ordinal Regression, and Survival Analysis. Cham: Springer, 2015

26. Hodges SD, Humphreys SC, Eck JC, Covington LA, Harrom $\mathrm{H}$ : Predicting factors of successful recovery from lumbar spine surgery among workers' compensation patients. J Am Osteopath Assoc 101:78-83, 2001

27. Ko SB, Lee SW: Prevalence of spondylolysis and its relationship with low back pain in selected population. Clin Orthop Surg 3:34-38, 2011

28. Langley GB, Sheppeard H: The visual analogue scale: its use in pain measurement. Rheumatol Int 5:145-148, 1985

29. Levin JM, Winkelman RD, Smith GA, Tanenbaum JE, Benzel EC, Mroz TE, et al: Impact of preoperative depression on hospital consumer assessment of healthcare providers and systems survey results in a lumbar fusion population. Spine (Phila Pa 1976) 42:675-681, 2017

30. Luo X, Pietrobon R, Sun SX, Liu GG, Hey L: Estimates and patterns of direct health care expenditures among individuals with back pain in the United States. Spine (Phila Pa 1976) 29:79-86, 2004

31. Maxwell TD, Gatchel RJ, Mayer TG: Cognitive predictors of depression in chronic low back pain: toward an inclusive model. J Behav Med 21:131-143, 1998

32. McGirt MJ, Speroff T, Dittus RS, Harrell FE Jr, Asher AL: The National Neurosurgery Quality and Outcomes Database $\left(\mathrm{N}^{2} \mathrm{QOD}\right)$ : general overview and pilot-year project description. Neurosurg Focus 34(1):E6, 2013

33. Meyerding HW: Diagnosis and roentgenologic evidence in spondylolisthesis. Radiology 20:108-120, 1933

34. Mroz TE, Norvell DC, Ecker E, Gruenberg M, Dailey A, Brodke DS: Fusion versus nonoperative management for chronic low back pain: do sociodemographic factors affect outcome? Spine (Phila Pa 1976) 36 (21 Suppl):S75-S86, 2011

35. Mummaneni PV, Bisson EF, Kerezoudis P, Glassman S, Foley $\mathrm{K}$, Slotkin JR, et al: Minimally invasive versus open fusion for Grade I degenerative lumbar spondylolisthesis: analysis of the Quality Outcomes Database. Neurosurg Focus 43(2):E11, 2017

36. Parker SL, Godil SS, Zuckerman SL, Mendenhall SK, Devin $\mathrm{CJ}, \mathrm{McGirt} \mathrm{MJ}$ : Extent of preoperative depression is associated with return to work after lumbar fusion for spondylolisthesis. World Neurosurg 83:608-613, 2015

37. Sigmundsson FG, Jönsson B, Strömqvist B: Determinants of patient satisfaction after surgery for central spinal stenosis without concomitant spondylolisthesis: a register study of 5100 patients. Eur Spine J 26:473-480, 2017

38. Stewart WF, Ricci JA, Chee E, Morganstein D, Lipton R: Lost productive time and cost due to common pain conditions in the US workforce. JAMA 290:2443-2454, 2003

39. Strøm J, Bjerrum MB, Nielsen CV, Thisted CN, Nielsen TL, Laursen M, et al: Anxiety and depression in spine surgery-a systematic integrative review. Spine J 18:1272-1285, 2018

40. Than KD, Curran JN, Resnick DK, Shaffrey CI, Ghogawala Z, Mummaneni PV: How to predict return to work after lumbar discectomy: answers from the NeuroPoint-SD registry. J Neurosurg Spine 25:181-186, 2016

41. Weinstein JN, Lurie JD, Tosteson TD, Hanscom B, Tosteson ANA, Blood EA, et al: Surgical versus nonsurgical treatment for lumbar degenerative spondylolisthesis. N Engl J Med 356:2257-2270, 2007

\section{Disclosures}

Dr. Mummaneni reports the following: consultant for DePuy 
Spine, Globus Medical, and Stryker; direct stock ownership in Spinicity/ISD; clinical or research support for the present study from NREF; support of non-study-related clinical or research work that he oversees from ISSG; honoraria from Spineart and AOSpine; and royalties from DePuy Spine, Thieme Medical Publishers, and Springer Publishing. Dr. Chan reports support of non-study-related clinical or research work that he oversees from Orthofix. Dr. Glassman reports the following: employed by Norton Healthcare; patent holder with Medtronic; a nonfinancial relationship with the Scoliosis Research Society; and consultant for Medtronic and K2M. Dr. Foley reports the following: consultant for Medtronic; direct stock ownership in Medtronic, Discgenics, Durastat, Digital Surgical Solutions, and NuVasive; patent holder with Medtronic; royalties for patents from Medtronic; and board of directors with Discgenics, Durastat, and Digital Surgical Solutions. Dr. C. Shaffrey reports the following: direct stock ownership in NuVasive; patent holder with NuVasive, Medtronic, and Zimmer Biomet; and consultant for NuVasive, Medtronic, and EOS. Dr. Coric reports the following: consultant for Spine Wave, Medtronic, Globus Medical, Stryker, Integrity Implants, and Premia Spine; and direct stock ownership in Spine Wave. Dr. Park reports being a consultant for Globus Medical, NuVasive, Medtronic, and Allosource and receiving royalties from Globus Medical. Dr. Wang reports being a consultant for DePuy Synthes, K2M, Stryker, and Spineology; being a patent holder with DePuy Synthes; and direct stock ownership in ISD and Medical Device Partners. Dr. Slotkin reports being a consultant for Stryker and Medtronic. Dr. Virk reports being a consultant for Globus Medical and DePuy Synthes. Dr. Haid reports receiving royalties from
NuVasive, Globus Medical, Medtronic Sofamor Danek, and Elsevier; being a consultant for NuVasive; and direct stock ownership in NuVasive, Spine Wave, and Vertical Health. Dr. Bisson reports being a consultant for nView.

\section{Author Contributions}

Conception and design: Bydon, Mummaneni. Acquisition of data: Alvi, Chan. Analysis and interpretation of data: Alvi, Chan. Drafting the article: Bydon, Mummaneni, Alvi, Chan. Critically revising the article: Bydon, Mummaneni, Alvi, Chan, Glassman, Foley, Potts, CI Shaffrey, ME Shaffrey, Knightly, Park, Wang, Fu, Slotkin, Asher, Virk, Kerezoudis, Guan, Haid, Bisson. Reviewed submitted version of manuscript: all authors. Approved the final version of the manuscript on behalf of all authors: Bydon. Statistical analysis: Mummaneni, Alvi, Coric. Administrative/technical/ material support: Bydon, Mummaneni. Study supervision: Bydon, Mummaneni.

\section{Supplemental Information \\ Videos \\ Video Abstract. https://vimeo.com/328716401.}

\section{Correspondence}

Mohamad Bydon: Mayo Clinic, Rochester, MN. bydon. mohamad@mayo.edu. 